\title{
PERBANDINGAN KADAR HEMOGLOBIN DARAH PADA PRIA PEROKOK DAN BUKAN PEROKOK
}

\author{
${ }^{1}$ Melkior T. Makawekes \\ ${ }^{2}$ Sonny J. R. Kalangi \\ ${ }^{2}$ Taufiq F. Pasiak
}

\author{
${ }^{1}$ Kandidat Skripsi Fakultas Kedokteran Universitas Sam Ratulangi Manado \\ ${ }^{2}$ Bagian Anatomi-Histologi Fakultas Kedokteran Universitas Sam Ratulangi Manado \\ Email: melki.makawekes@gmail.com
}

\begin{abstract}
Smoking habits have a bad effect for health, especially for respiratory organs. Various lung diseases arising from smoking include lung cancer and chronic obstructive pulmonary disease. In Indonesia, the prevalence of smokers is increasing not only men but also women. This study was performed to compare the levels of hemoglobin blood of smokers and nonsmokers in male students semester seventh of Faculty of Medicine, University of Sam Ratulangi. This study was an observational study. The population in this study is male students semester seventh of Faculty of Medicine, University of Sam Ratulangi period January 2012. The total sample is 60 students, consisting of 30 smokers students and 30 nonsmokers students. Based on research data, average values of blood hemoglobin that is 16.263 (mg / dl), with a standard deviation of 0.9320 (mg / dl), whereas in the study sample 30 male nonsmokers had an average value of blood hemoglobin that is 15.723 (mg / dl), with a standard deviation of 0.8207 (mg / dl). Results of this study concluded that statistically there is comparison blood hemoglobin levels in student semester seventh period 2012 Faculty of Medicine, University of Sam Ratulangi both smokers and non smokers.
\end{abstract}

Keywords: hemoglobin, male smokers and nonsmokers.

\begin{abstract}
Abstrak: Kebiasaan merokok mempunyai dampak yang buruk terhadap kesehatan terutama pada organ pernafasan. Berbagai penyakit paru timbul akibat rokok antara lain kanker paru dan penyakit paru obstruktif kronik. Di Indonesia prevalensi perokok makin meningkat tidak saja laki-laki namun juga pada perempuan. Penelitian ini dilakukan untuk mengetahui perbandingan kadar hemoglobin darah perokok dan bukan perokok pada mahasiswa pria Fakultas Kedokteran Universitas Sam Ratulangi semester tujuh. Adapun penelitian ini adalah penelitian observasional. Populasi dalam penelitian ini seluruh mahasiswa pria semester 7 Fakultas Kedokteran Universitas Sam Ratulangi Manado periode Januari 2012. Jumlah sampel 60 mahasiswa, yang terdiri dari 30 mahasiswa perokok dan 30 mahasiswa bukan perokok. Berdasarkan data hasil penelitian didapatkan nilai rata-rata hemoglobin darah yaitu 16,263 (mg/dl), dengan standar deviasi 0,9320 (mg/dl), sedangkan pada sampel penelitian 30 pria bukan perokok memiliki nilai rata-rata hemoglobin darah yaitu 15,723 (mg/dl), dengan standar deviasi 0,8207 (mg/dl). Hasil penelitian ini menyimpulkan bahwa secara statistik ada perbandingan kadar hemoglobin darah mahasiswa semester tujuh tahun ajaran 2012 Fakultas Kedokteran Universitas Sam Ratulangi Manado yang perokok dan bukan perokok
\end{abstract}

Kata kunci: kadar hemoglobin, pria perokok dan bukan perokok.

Rokok merupakan salah satu olahan tembakau dengan menggunakan bahan ataupun tanpa bahan tambahan. Rokok dengan bahan tambahan berupa cengkeh disebabkan rokok kretek, sedangkan rokok tanpa bahan tambahan cengkeh disebut 
sebagai rokok putih. ${ }^{1}$ Selain salah satu olahan tembakau, rokok juga merupakan salah satu zat adiktif yang bila digunakan dapat mengakibatkan bahaya kesehatan bagi individu dan masyarakat. ${ }^{2}$

Kebiasaan merokok mempunyai dampak yang buruk terhadap kesehatan terutama pada organ pernafasan. Berbagai penyakit paru timbul akibat rokok antara lain kanker paru dan penyakit paru obstruktif kronik (PPOK). Di Indonesia prevalensi perokok makin meningkat tidak saja laki-laki namun juga pada perempuan. lebih memprihatinkan makin banyak perokok sudah dimulai pada usia yang sangat dini. ${ }^{3}$

Umur mulai merokok pada usia anak mengalami peningkatan, demikian pula umur mulai merokok pada usia remaja dan dewasa muda mengalami peningkatan. Menurut data hasil Riset Kesehatan Dasar (Riskesdas) tahun 2007 dan 2010 terjadi kecenderungan peningkatan umur mulai merokok pada usia yang lebih muda. Menurut Riskesdas 2007, umur pertama kali merokok pada usia 5-9 tahun sebesar $1,2 \%$, pada usia 10-14 tahun sebesar $10,3 \%$, pada usia 15-19 tahun sebesar $33,1 \%$, pada usia 20-24 tahun sebesar $12,1 \%$, pada usia 25-29 tahun sebesar 3,4\% dan pada usia $\geq 30$ tahun sebesar $4 \%$. Sedangkan menurut Riskesdas 2010, umur pertama kali merokok pada usia 5-9 tahun sebesar $1,7 \%$, pada usia 10-14 tahun sebesar 17,5\%, pada usia 15-19 tahun sebesar 43,3\%, pada usia 20-24 tahun sebesar 14,6\%, pada usia 25-29 tahun sebesar $4,3 \%$ dan pada usia $\geq 30$ tahun sebesar $3,9 \%{ }^{4}$

Hemoglobin merupakan salah satu senyawa dalam sel darah merah yang berfungsi mengangkut zat oksigen ke dalam sel-sel tubuh. ${ }^{5}$ Menurut penelitian John W. Adamson (2005) yang menyatakan pada perokok berat terjadi peningkatan kadar hemoglobin. Peningkatan ini terjadi karena reflek dari mekanisme kompensasi tubuh terhadap rendahnya kadar oksigen yang berikatan dengan hemoglobin akibat digeser oleh karbon monoksida yang mempunyai afinitas terhadap hemoglobin yang lebih kuat. Sehingga tubuh akan meningkatkan proses hematopoiesis lalu meningkatkan produksi hemoglobin, akibat dari rendahnya tekanan parsial oksigen $\left(\mathrm{PO}_{2}\right)$ di dalam tubuh. ${ }^{6}$

\section{METODE PENELITIAN}

Penelitian ini adalah penelitian observasional dan merupakan desain penelitian cross sectional. Dilakukan pada bulan Desember 2012 di Fakultas Kedokteran Universitas Sam Ratulangi Manado. Populasi dan sampel dalam penelitian ini seluruh mahasiswa pria semester 7 Fakultas Kedokteran Universitas Sam Ratulangi Manado periode Januari 2012, di mana data sampel yang diambil adalah mahasiswa pria semester 7 Fakultas Kedokteran Universitas Sam Ratulangi Manado yang memenuhi kriteria inklusi dan bersedia menjadi objek penelitian. Jumlah sampel 60 mahasiswa, yang terdiri dari 30 mahasiswa mahasiswa perokok dan 30 mahasiswa mahasiswa bukan perokok.

\section{HASIL PENELITIAN}

Berdasarkan hasil pengumpulan data, karakteristik sampel penelitian berdasarkan umur dapat dilihat pada tabel berikut:

Tabel 1. Distribusi Sampel Penelitian Berdasarkan Umur.

\begin{tabular}{lcc}
\hline Umur & n & \% \\
\hline 19 & 4 & 6 \\
20 & 15 & 25 \\
21 & 25 & 42 \\
22 & 13 & 22 \\
23 & 3 & 5
\end{tabular}

Dari Tabel 1 jumlah sampel 60 mahasiswa dengan presentase tertinggi umur 21 tahun sebanyak 25 mahasiswa (42\%), dan terkecil umur 23 tahun sebanyak tiga mahasiswa (5\%).

Pada Tabel 2 sampel penelitian 30 pria perokok memiliki nilai rata-rata hemoglobin darah yaitu 16,263 (mg/dl), dengan standar deviasi 0,9320 (mg/dl), 
memiliki nilai tertinggi $18,9(\mathrm{mg} / \mathrm{dl})$ dan nilai terendah $14,1(\mathrm{mg} / \mathrm{dl})$, sedangkan pada sampel penelitian 30 pria bukan perokok memiliki nilai rata-rata hemoglobin darah yaitu 15,723 (mg/dl), dengan standar deviasi 0,8207 (mg/dl), memiliki nilai tertinggi $17,3(\mathrm{mg} / \mathrm{dl})$ dan nilai terendah 13,9 (mg/dl).

Tabel 2. Distribusi Sampel Penelitian Berdasarkan Kadar Hemoglobin Darah Pada 30 Pria Perokok dan 30 Pria Bukan Perokok.

\begin{tabular}{lc}
\hline $\begin{array}{l}\text { Kadar Hb Darah } \\
\text { Pada } \mathbf{3 0} \text { Pria } \\
\text { Perokok }\end{array}$ & $\begin{array}{c}\text { Hemoglobin } \\
\text { (mg/dL) }\end{array}$ \\
\hline Rata-Rata & 16,263 \\
Standar Deviasi & 0,9320 \\
Nilai Tertinggi & 18,9 \\
Nilai Terendah & 14,1 \\
\hline Kadar Hb Darah & $\mathbf{\%}$ \\
Pada 30 Pria & \\
Bukan Perokok & \\
\hline Rata-Rata & 15,723 \\
Standar Deviasi & 0,8207 \\
Nilai Tertinggi & 17,3 \\
Nilai Terendah & 13,9 \\
\hline
\end{tabular}

Tabel 3: Hasil Uji Normalitas Sebaran Data dan Hasil Perhitungan Menggunakan Uji Independent Sampel T-Test Kadar Hemoglobin Darah Pada Perokok dan Bukan Perokok.

\begin{tabular}{lcc}
\hline Hemoglobin & P-Value & Keterangan \\
\hline $\begin{array}{l}\text { Perokok dan } \\
\text { Bukan } \\
\text { Perokok }\end{array}$ & 0,200 & Normal \\
\hline Test & & \\
\hline $\begin{array}{l}\text { Independent } \\
\text { sample t-test }\end{array}$ & 0,021 & $\begin{array}{c}\text { Heputusan } \\
\text { diterima }\end{array}$ \\
\hline
\end{tabular}

Pada Tabel 3 berdasarkan perhitungan menggunakan uji kolmogorov-smirnov ${ }^{a}$ dari kadar kolesterol high desnity lipoprotein darah perokok dan bukan perokok, maka hasil yang didapatkan yaitu 0,200 . Suatu data dinyatakan berdistribusi normal jika nilai probabilitasnya lebih besar dari 0,05. Dari hasil yang didapatkan yaitu 0,200 maka dapat disimpulkan bahwa data berasal dari populasi yang berdistribusi normal. Jadi uji alternatif yang digunakan adalah independent sample t-test. Sedangkan berdasarkan perhitungan menggunakan uji independent sample t-test kadar hemoglobin darah pada perokok dan bukan perokok dapat diambil keputusan bahwa ada perbandingan antara penurunan kadar Hemoglobin darah pada perokok dan bukan perokok.

\section{BAHASAN}

Rokok adalah olahan tembakau yang menggunakan bahan atau tanpa bahan, selain itu rokok juga merupakan zat adiktif yang berbahaya bagi tubuh manusia dan merupakan salah satu penyebab timbulnya penyakit gangguan pernapasan. ${ }^{1,2,3}$ Rokok juga dapat meningkatkan produksi hemoglobin darah.

Dalam penelitian ini dibandingkan kadar hemoglobin darah pada pria perokok dan bukan perokok mahasiswa Fakultas Kedokteran Universitas Sam Ratulangi Manando semester tujuh tahun.ajaran 2012 Penelitian ini dilakukan di gedung Pertamina Universitas Sam Ratulangi Manado dan Laboratorium Medistar Manado dimana masing-masing responden sebanyak 60 pria, 30 perokok dan 30 bukan perokok yang sesuai kriteria inklusi dan eksklusi diambil sampel darahnya kemudian diperiksa kadar hemoglobin darah di Laboratorium Medistar setelah didapatkan hasilnya data diuji normalitasnya dengan uji kolmogorovsmirnov. Perhitungan dilakukan sebelum data dilakukan pengujian hipotesis. Berdasarkan hasil perhitungan menggunakan uji komogorov-smirnov dari kadar hemoglobin darah pada perokok dan bukan perokok mempunyai nilai probabilitas (p-value) sebesar 0,00. Pengujian tentang sebaran data telah dilakukan dan hasilnya disimpulkan bahwa data berasal dari populasi yang berdistribusi normal maka selanjutnya pengujian hipotesis dapat dilakukan dengan menggunakan uji independent sample ttest. Pengujian hipotesis menggunakan bantuan program Statistical Program for Social Sciene 20 (SPSS 20).

Setelah diuji dengan menggunankan uji alternatif dari uji t yaitu mann-whitney 
diperoleh nilai hitung sebesar 0,021. Ho ditolak jika nilai probabilitas kurang dari 0,05 karena nilai probabilitas yang didapat dalam perhitungan kurang dari 0,05 maka dengan demikian Ho ditolak dan dapat disimpulkan bahwa hipotesis alternatif yang menyatakan ada perbandingan kadar hemoglobin darah pada perokok dan bukan perokok terbukti kebenarannya secara statistik.

Pada penelitian yang dilakukan Ahmad Asyraf Bin Zukefeli dengan judul hubungan merokok dengan kadar hemoglobin darah pada warga dengan jenis kelamin pria berusia 18-40 tahun yang tinggal di Bandara Putra Bertam, kepala batas, pulau pinang, Malaysia didapatkan perbedaan kadar hemoglobin rata-rata pada kelompok merokok dan kelompok tidak merokok. Pada kelompok merokok nilai rata-ratanya $13,77 \mathrm{~g} / \mathrm{dl}$ dengan standar deviasi 1,43 nilai ini lebih tinggi dibandingkan dengan kadar hemoglobin rata-rata pada kelompok tidak merokok yaitu 12,53 g/dl dengan standar deviasi 1,42. Setelah dilakukan uji $\mathrm{T}$ independen didapatkan hasil nilai $p$ yaitu 0,000 yang berart lebih kecil dari 0,05. ${ }^{6}$

Pada penelitian sebelumnya menyatakan terdapat perbedaan kadar hemoglobin yang menguatkan penelitian ini, dimana hasil yang didapatkan bahwa ada perbedaan secara statistik kadar hemoglobin darah pada pria perokok dan bukan perokok di mahasiswa semester tujuh Fakultas Kedokteran Universitas Sam Ratulangi Manado, pada penelitian ini didapatkan kadar hemoglobin darah pada perokok lebih tinggi dari pada bukan perokok. Sehingga penelitian ini dan sebelumnya mempunyai hubungan kuat.

\section{SIMPULAN}

Nilai rata-rata kadar hemoglobin darah pada mahasiswa semeseter tujuh tahun ajaran 2012 Fakultas Kedokteran Universitas Sam Ratulangi Manado yang perokok sebesar 16,263 (mg/dL). Nilai rata-rata kadar hemoglobin darah pada mahasiswa semester tujuh tahun ajaran 2012 Fakultas Kedokteran Universitas Sam
Ratulangi Manado yang bukan perokok sebesar 15,723 (mg/dL). Secara statistik ada perbandingan kadar hemoglobin darah mahasiswa semeseter tujuh tahun ajaran 2012 Fakultas Kedokteran Universitas Sam Ratulangi Manado yang perokok dan bukan perokok.

\section{SARAN}

1. Untuk penelitian yang lebih lanjut agar menggunakan sampel yang lebih banyak lagi sehingga dapat memberikan hasil yang lebih signifikan.

2. Masyarakat berusaha agar mengurangi aktifitas merokok dimana sudah banyak penelitian yang menunjukan efek - efek kurang baik yang ditimbulkan oleh peperan asap rokok.

3. Perbanyak aktifitas olah raga yang teratur dan menghindari kebiasaan buruk.

\section{DAFTAR PUSTAKA}

1. Sukmaningsih A. Penurunan jumlah spermatosit pakiten dan spermatid tubulus seminiferus testis mencit (Mus musculus) yang dipaparkan asap rokok. Jurnal Biologi. 2009. p.31-35.

2. Aina N. Pengaruh paparan asap rokok terhadap spermatogenesis dan kualitas spermatozoa mencit (Mus musculus L.) galur Swiss [skripsi]. UNS. 2005. p.1-21.

3. Stratton $K$, Shetty $P$, Wallace $R$, Bondurant S. Clearing the smoke assesing the science base for tobacco harm reduction. Washington: National Academy Press Institute of Medicine, 2001.

4. Badan Penelitian dan Pengembangan Kesehatan Riset Kesehatan Dasar 2007 Kementerian Kesehatan RI 2007.

5. Murray RK. Sel Darah Merah dan Putih. In: Murray RK, Granner DK, Rodwell VW, editors. Biokimia Harper. Jakarta: EGC, 2006; p.636652.

6. Zukefeli A, A, B. Hubungan Merokok Dengan Kadar Hemoglobin Pada Warga Dengan Jenis Kelamin LakiLaki Berusia 18-40 Tahun Yang 
Jurnal e-Biomedik (eBm), Volume 4, Nomor 1, Januari-Juni 2016

Tinggal Di Bandar Putra Bertam,

Malaysia. [skripsi]. Medan:

Kepala Batas, Pulau Pinang,

Universitas Sumatera Utara; 2010. 